\title{
ESTABELECIMENTO IN VITRO DE GEMAS AXILARES DE ABACAXIZEIRO EM FUNÇÃO DA VARIAÇÃO DA CONCENTRAÇÃO DE 6- BENZILAMINOPURINA
}

\author{
lasmin Laís Damasceno Paranatinga'; Tanara Pletsch Dalla Costa²; Rômulo Jorge Batista Pereira³; João \\ Marcos Pereira Galúcio4; Eliandra de Freitas $\mathrm{Sia}^{5}$.

\footnotetext{
${ }^{1}$ Universidade Federal do Oeste do Pará, Santarém, Pará, Brasil, iasminlais@hotmail.com ${ }^{2}$ Universidade Federal do Oeste do Pará, Santarém, Pará, Brasil, tanara_dallacosta@hotmail.com

3 Universidade Federal do Oeste do Pará, Santarém, Pará, Brasil, romulo.jorge55@gmail.com

${ }^{4}$ Universidade Federal do Oeste do Pará, Santarém, Pará, Brasil,.jmpgalucio@gmail.com

${ }^{5}$ Universidade Federal do Oeste do Pará, Santarém, Pará, Brasil, eliandra.sia@hotmail.com
}

RESUMO: A micropropagação é uma técnica da cultura de tecidos vegetais que se destaca na obtenção de plantas saudáveis, aplicada com sucesso na produção em larga escala de variedades comercias de abacaxi. No entanto, estudos com variedades selvagens do gênero Ananas apresentaram baixas taxas de multiplicação. Sendo assim, o objetivo desta pesquisa foi avaliar o efeito da variação da concentração de 6-benzilaminopurina (BAP) no estabelecimento in vitro de gemas axilares de Ananas comosus cv. Pérola. Foram avaliados seis tratamentos, sendo eles: MS isento de reguladores (T1); 0,0 (T2); 0,025 (T3); 0,05 (T4); 0,1 (T5); 0,2 $\mathrm{mg} \mathrm{L}^{-1}$ de BAP (T6), combinados com $0,01 \mathrm{mg} \mathrm{L}^{-1}$ de ácido naftalenoacético (ANA). O experimento foi conduzido em delineamento inteiramente casualizado, contendo dezesseis repetições por tratamento, cuja unidade experimental foi constituída de um explante por tubo de ensaio. Os tratamentos 2, 3, 4 e 5 atingiram o estabelecimento máximo com 21 dias de cultivo in vitro, enquanto o tratamento 1 não obteve o estabelecimento máximo e 0 tratamento 6 obteve apenas aos 37 dias de cultivo. Sendo assim, nota-se que concentrações de BAP entre 0,025 a 0,1 $\mathrm{mg} \mathrm{L}^{-1}$ aceleram o estabelecimento de gemas axilares de abacaxi e, em contrapartida, a ausência de reguladores de crescimento ou altas concentrações de BAP interferem negativamente no seu estabelecimento in vitro. A variação da concentração de 6 -benzilaminopurina (BAP) não influenciou no número de explantes estabelecidos in vitro após 37 dias de cultivo. Na ausência de regulador de crescimento vegetal há baixa taxa de brotações dos explantes.

PALAVRAS-CHAVE: Cultura in vitro, Micropropagação, Reguladores de crescimento. 


\title{
IN VITRO ESTABLISHMENT OF AXILLARY BUDS OF PINEAPPLE AS A FUNCTION OF THE CONCENTRATION VARIATION OF 6- BENZYLAMINOPURINE
}

\begin{abstract}
Micropropagation is a technique of plant tissue culture that excels in obtaining healthy plants, successfully applied in the large-scale production of commercial varieties of pineapple. However, studies with wild varieties of the genus Ananas presented low multiplication rates. Therefore, the objective of this research was to evaluate the effect of the variation of the concentration of 6benzylaminopurine (BAP) in the in vitro establishment of axillary buds of Ananas comosus cv. Pearl. Six treatments were evaluated, being: MS free from regulators (T1); 0.0 (T2); 0.025 (T3); 0.05 (T4); 0.1 (T5); 0.2 mg L-1 of BAP (T6), combined with $0.01 \mathrm{mg}$ $\mathrm{L}-1$ of naphthaleneacetic acid (ANA). The experiment was conducted in a completely randomized design, containing sixteen replicates per treatment, whose experimental unit consisted of one explant per test tube. Treatments 2, 3, 4 and 5 reached maximum establishment with 21 days of culture in vitro, while treatment 1 did not reach the maximum establishment and treatment 6 obtained only at 37 days of culture. Thus, it is noted that BAP concentrations between 0.025 and $0.1 \mathrm{mg} \mathrm{L}-1$ accelerate the establishment of axillary buds of pineapple and, in contrast, the absence of growth regulators or high concentrations of BAP interferes negatively in its establishment in vitro. The concentration variation of 6-benzylaminopurine (BAP) did not influence the number of explants established in vitro after 37 days of culture. In the absence of plant growth regulator there is a low explant bud rate.
\end{abstract}

KEYWORDS: Culture in vitro, Growth regulators, Micropropagation.

\section{ESTABLECIMIENTO IN VITRO DE GEMAS AXILARES DE PIÑA EN FUNCIÓN DE LA VARIACIÓN DE LA CONCENTRACIÓN DE 6- BENZILAMINOPURINA}

RESUMEN: La micropropagación es una técnica del cultivo de tejidos vegetales que se destaca en la obtención de plantas sanas, aplicada con éxito en la producción a gran escala de variedades comerciales de piña. Sin embargo, estudios con variedades salvajes del género Ananas presentaron bajas tasas de multiplicación. Por lo tanto, el objetivo de esta investigación fue evaluar el efecto de la variación de la concentración de 6-benzilaminopurina (BAP) en el establecimiento in vitro de gemas axilares de Ananas comosus cv. Perla. Se evaluaron seis tratamientos, siendo ellos: MS exento de reguladores (T1); 0,0 (T2); 0,025 (T3); 0,05 (T4); 0,1 (T5); 0,2 mg L-1 de BAP (T6), combinados con $0,01 \mathrm{mg} \mathrm{L-1}$ de ácido naftalenoacético (ANA). El experimento fue 
conducido en delineamiento completamente casualizado, conteniendo dieciséis repeticiones por tratamiento, cuya unidad experimental fue constituida de un explante por tubo de ensayo. Los tratamientos 2, 3, 4 y 5 alcanzaron el establecimiento máximo con 21 días de cultivo in vitro, mientras que el tratamiento 1 no obtuvo el establecimiento máximo y el tratamiento 6 sólo obtuvo a los 37 días de cultivo. Por lo tanto, se observa que las concentraciones de BAP entre 0,025 a 0,1 mg L-1 aceleran el establecimiento de gemas axilares de piña $y$, en contrapartida, la ausencia de reguladores de crecimiento o altas concentraciones de BAP interfieren negativamente en su establecimiento in in vitro. La variación de la concentración de 6benzilaminopurina (BAP) no influenció en el número de explantes establecidos in vitro después de 37 días de cultivo. En ausencia de regulador de crecimiento vegetal hay baja tasa de brotes de los.

PALABRAS CLAVE: Reguladores de crecimiento, Cultura in vitro, Micropropagación.

\section{INTRODUÇÃO}

O abacaxizeiro (Ananas comosus) é membro da família Bromeliaceae e acredita-se que tenha se originado na América do Sul das terras baixas, talvez no sudoeste do Brasil, região da bacia Paraná-Paraguai (CLEMENT et al., 2010). Esta cultura é propagada vegetativamente e seu propágulo principal, a coroa, pode suportar meses sem água, mas também pode tolerar níveis anuais de até $5500 \mathrm{~mm}$ (HOSSAIN et al., 2015). O abacaxi é o principal produto da planta de abacaxizeiro. A parte comestível da fruta é desenvolvida a partir de carpelos gastos, bases de sépalas e brácteas de mais de 200 flores fundidas e a superfície do fruto é coberta por sépalas, brácteas e os ápices dos ovários (BOTELLA; SMITH, 2008).

Atualmente, o abacaxi está presente em mais de 85 países, onde o Brasil entra no ranking como um dos maiores produtores mundiais desta cultura, com uma produção de 1,6 milhões de frutos, abrangendo uma área de 64 mil ha no ano de 2015. Os estados do Pará, Paraíba e Minas Gerais são os principais produtores nacionais de abacaxi (IBGE, 2015 apud MENDES et al., 2015).

A utilização de material propagativo de boa qualidade é necessária para 
que se obtenha sucesso em qualquer atividade agrícola. $\mathrm{Na}$ cultura do abacaxi há carência na disponibilidade de mudas em qualidade e quantidade aos produtores, uma vez, que a demanda de material propagativo é grande no qual, dependendo do espaçamento, em uma área de 1,0 ha, são necessárias de 35.000 a 70.000 mudas (ARAUJO et al., 2008; SANTOS et al., 2011). No que se refere a produção de mudas por planta, a taxa média é relativamente baixa, variando de três a seis mudas (COELHO et al., 2007). Aliado a isso, as plantas que apresentam frutos acometidos por doenças produzem mudas infectadas, o que gera perdas em torno de $20 \%$ do material propagativo e 30\% da produção (AQUIJE et al., 2010).

Neste sentido, a cultura de tecidos vegetais aliada à micropropagação é uma técnica útil para a obtenção de plantas saudáveis, que foram aplicadas com sucesso na produção em larga escala de variedades comerciais de abacaxi (PASQUAL et al., 2008; SANTOS et al., 2008; CARVALHO et al.,
2009; FRÁGUAS et al., 2009; SOUZA et al., 2009). No entanto, estudos com variedades selvagens do gênero Ananas apresentaram baixas taxas de multiplicação e presença de bactérias endógenas que sugerem que muitos protocolos devem ser revisados (SOUZA et al., 2009).

A resposta in vitro de uma planta depende de vários fatores, tais como espécies, genótipos, explantes iniciais e meio de cultura. Sendo assim, o ajuste médio da cultura é um dos aspectos mais relevantes para obter altas taxas de multiplicação e plantas saudáveis. Portanto, o objetivo desta pesquisa foi avaliar o efeito da variação da concentração de 6-benzilaminopurina (BAP) no estabelecimento in vitro de gemas axilares de Ananas comosus cv. Pérola.

\section{MATERIAL E MÉTODOS}

O experimento foi conduzido em agosto de 2017 no Laboratório de Estudo dos Ecossistemas Amazônicos (LEEA), pertencente ao Instituto de Biodiversidade e Florestas (IBEF) da 
Universidade Federal do Oeste do Pará, município de Santarém, Pará.

Inicialmente, as plantas matrizes de abacaxizeiro da variedade Pérola oriundas do campo foram selecionadas visualmente com base em suas características fenotípicas e coletadas como fonte de explantes. Em seguida, foi realizada a extração das gemas, na qual as folhas foram retiradas, preservando o explante, sendo este extraído, preferencialmente, do terço médio e superior do caule.

Posteriormente, foi realizado o processo de desinfestação dos explantes em cabine de fluxo laminar, no qual as gemas foram imersas em álcool 70\% por um período de cinco minutos, em seguida transferidas para uma solução de hipoclorito de sódio comercial e água deionizada esterilizada, na proporção de 1:1, onde permaneceram 30 minutos e, por fim, estas foram lavadas três vezes consecutivas em água deionizada esterilizada.

Após a assepsia, com auxílio de uma pinça e bisturi, os explantes foram reduzidos para obtenção de blocos de
0,5 a 1,0 cm de tamanho. Estes explantes foram transferidos para tubos de ensaio contendo $10 \mathrm{ml}$ do meio de estabelecimento, previamente esterilizado. O meio de cultura empregado foi composto pelos sais minerais do MS (Murashige \& Skoog, 1962), suplementado com tiamina-HCL (1 mg L-1), inositol (100 mg L-1), sacarose (30 g L-1), reguladores de crescimento em diferentes concentrações e gelificado com Phytagel (1,8 g L-1). $\bigcirc$ pH do meio de cultura foi ajustado para 5,7 $\pm 0,1$ antes da autoclavagem a $121^{\circ} \mathrm{C}$ e $1 \mathrm{~atm}$, por 20 min.

Foram avaliados seis tratamentos, sendo eles: 0,0 mg L-1 de 6benzilaminopurina (BAP) e 0,0 mg L-1 de ácido naftalenoacético (ANA) (T1); 0,0 mg L-1 de BAP e 0,01 mg L-1 de ANA (T2); 0,025 mg L-1 de BAP e 0,01 de mg L-1 ANA (T3); 0,05 mg L-1 de BAP e 0,01 mg L-1 ANA (T4); 0,1 mg L-1 de BAP e 0,01 mg L-1 de ANA (T5) e 0,2 mg L-1 de BAP e 0,01 mg L-1 de ANA (T6). O experimento foi conduzido na forma de delineamento inteiramente casualizado, contendo dezesseis repetições por 
tratamento, cuja unidade experimental foi constituída de um explante por tubo de ensaio.

Os tubos foram transferidos para a sala de crescimento, sob condições de temperatura de $27 \pm 1^{\circ} \mathrm{C}$, densidade de fluxo de fótons de $30 \mu \mathrm{mol} / \mathrm{m}^{2} / \mathrm{s}$ e fotoperíodo de 16 horas. Foram realizadas avaliações semanais, analisando-se o número de explantes estabelecidos e de brotações. Os dados obtidos foram submetidos à análise de regressão, ao nível de 5\% de probabilidade. $\mathrm{O}$ estabelecimento in vitro geralmente compreende um período de 30 a 45 dias para a cultura do abacaxi, período este em que começa a se esgotar os nutrientes do meio de cultura. Portanto, aos 37 dias após a introdução in vitro, foram determinados os percentuais de contaminação (fungo ou bactéria), oxidação da gema (morte), explantes estabelecidos e brotações.

\section{RESULTADOS E DISCUSSÃO}

De acordo com os resultados obtidos para o estabelecimento in vitro de abacaxizeiro cv. Pérola, submetido a diferentes concentrações de BAP (Figura 1), observa-se que todos os tratamentos se ajustaram ao modelo logarítmico, com valores de $\mathrm{R}^{2}$ superiores a $77 \%$, com exceção do tratamento 6, o qual melhor se ajustou ao modelo linear, com $\mathrm{R}^{2}=$ $94 \%$.

Verificou-se que o intumescimento dos explantes, ou seja, o aumento do volume e mudança de coloração das gemas, iniciou aos sete dias após a introdução do material in vitro, independentemente do tratamento. No entanto, os tratamentos 2, 3, 4 e 5 atingiram o estabelecimento máximo com 21 dias de cultivo in vitro, enquanto o tratamento 1 não obteve o estabelecimento máximo e o tratamento 6 obteve apenas aos 37 dias de cultivo. Sendo assim, nota-se que concentrações de BAP entre 0,025 a 0,1 mg L-1 aceleram o estabelecimento de gemas axilares de abacaxi e, em contrapartida, a ausência de reguladores de crescimento ou altas concentrações de BAP interferem negativamente no seu estabelecimento in vitro. 
Figura 1. Estabelecimento in vitro de gemas axilares de abacaxizeiro cv. Pérola submetidas a diferentes concentrações de BAP ao longo do tempo.

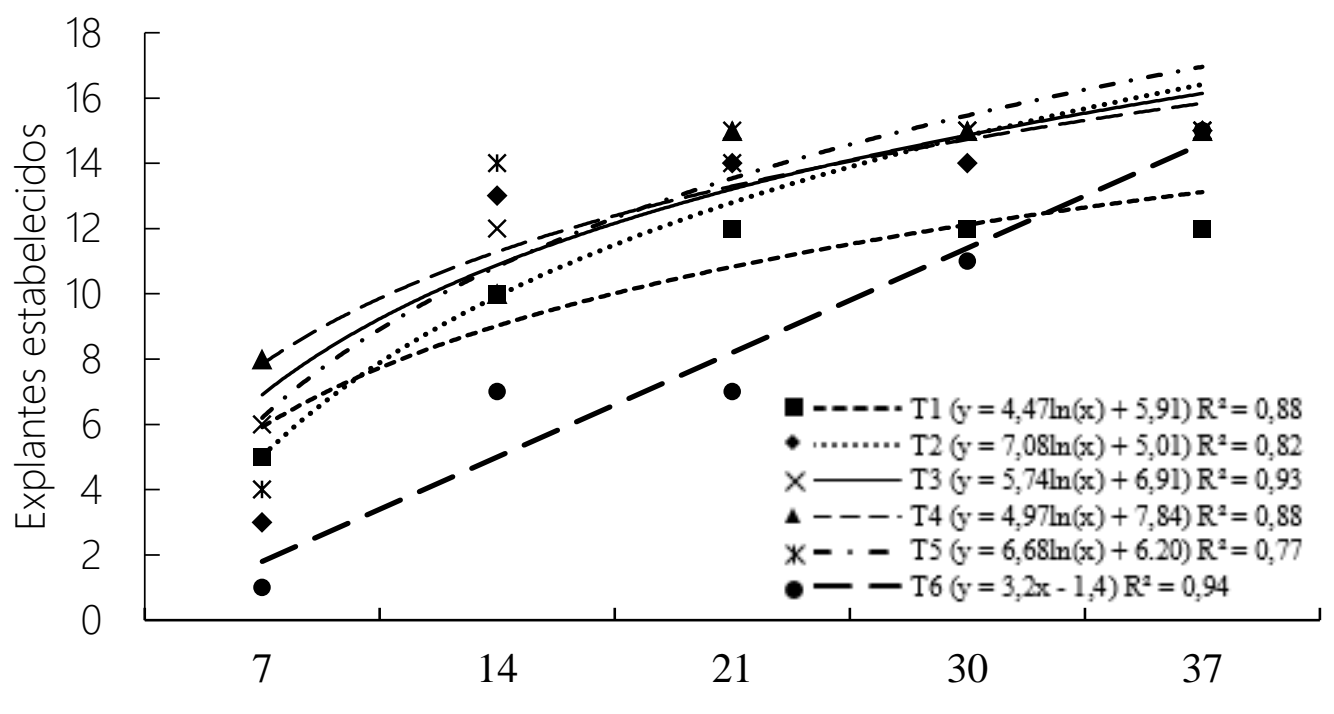

Dias de estabelecimento in vitro

Tratamentos: 0,0 mg L-1 BAP + 0,0 mg L-1 de ANA (T1); 0,0 $\mathrm{mg} \mathrm{L}^{-1}$ de BAP + 0,01 $\mathrm{mg} \mathrm{L}^{-1}$ de ANA (T2); $0,025 \mathrm{mg} \mathrm{L}^{-1}$ de BAP + 0,01 de mg L $\mathrm{L}^{-1}$ ANA (T3); 0,05 mg L-1 de BAP + 0,01 mg L-1 ANA (T4); 0,1 $\mathrm{mg} \mathrm{L}^{-1}$ de BAP + 0,01 mg L $\mathrm{L}^{-1}$ de ANA (T5) e 0,2 $\mathrm{mg} \mathrm{L}^{-1}$ de BAP + 0,01 mg L-1 de ANA (T6).

De acordo com Santos et al. (2008), das citocininas disponíveis comercialmente, o BAP é a que geralmente proporciona melhores resultados, cuja função na cultura de tecidos é estimular a divisão celular, atuando no processo de morfogênese. A utilização de BAP em combinação com ANA tem sido relatada em trabalhos de micropropagação de espécies do gênero Ananas (ARAUJO et al., 2008; SANTOS et al., 2008;
OLIVEIRA-CAUDURO et al., 2016). No entanto, o balanço entre BAP e ANA é dependente do genótipo, sendo importante sua otimização para obter máxima resposta morfogenética.

No que se refere ao número de brotações provenientes das gemas axilares de abacaxi cv. Pérola cultivadas in vitro (Figura 2), é possível observar que seu início ocorreu aos 14 dias de cultivo, porém, em apenas dois explantes, aumentando linearmente $\left(R^{2}\right.$ 
superior a 79\%) para todos os tratamentos ao longo do tempo de cultivo. Contudo, verificou-se que para o tratamento 1, isento de reguladores vegetais, houve baixo número de brotações, em comparação com os demais tratamentos.

Figura 2. Brotações de gemas axilares de abacaxizeiro cv. Pérola cultivadas in vitro e submetidas a diferentes concentrações de BAP ao longo do tempo.

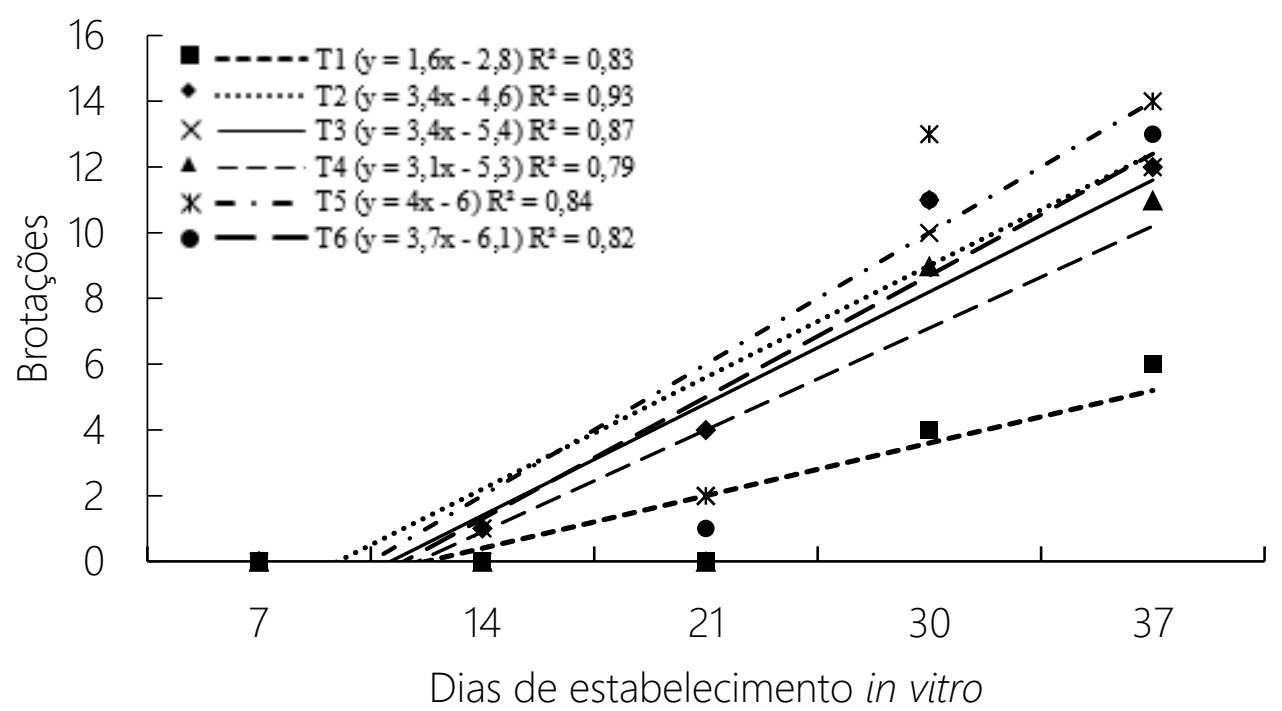

Tratamentos: 0,0 mg L-1 BAP + 0,0 mg L-1 de ANA (T1); 0,0 $\mathrm{mg} \mathrm{L}^{-1}$ de BAP + 0,01 $\mathrm{mg} \mathrm{L}^{-1}$ de ANA (T2); $0,025 \mathrm{mg} \mathrm{L}^{-1}$ de BAP + 0,01 de mg L $\mathrm{L}^{-1}$ ANA (T3); 0,05 mg L $\mathrm{L}^{-1}$ de BAP + 0,01 mg L-1 ANA (T4); 0,1 $\mathrm{mg} \mathrm{L}^{-1}$ de BAP + 0,01 mg L'-1 de ANA (T5) e 0,2 mg L-1 de BAP + 0,01 $\mathrm{mg} \mathrm{L}^{-1}$ de ANA (T6).

Aos 37 dias de cultivo in vitro, obteve-se os percentuais de contaminação, de oxidação, de estabelecimento e de brotações de gemas axilares de abacaxizeiro (Tabela 1). Quanto à taxa de contaminação, esta não passou de 7\% por tratamento, sendo totalmente de origem bacteriana. Esta é a forma mais comum de contaminação na cultura de tecidos (PICOLOTTO et al., 2007). A taxa de contaminação neste trabalho está dentro dos níveis aceitáveis para o cultivo in vitro, inferindo-se que o processo de assepsia foi eficiente. De acordo com Pereira et al. (2015), as 
substâncias mais utilizadas na assepsia dos explantes são compostos a base de hipoclorito de sódio e álcool, no qual o tempo e concentração em que o material vegetal será exposto é dependente da cultura. Moraes et al.
(2007), obtiveram $\quad 100 \%$ de desinfestação de gemas axilares de abacaxizeiro em concentrações de 2, 3 e $4 \%$ de $\mathrm{NaClO}$ durante 15 minutos de exposição.

Tabela 1. Percentuais de contaminação, de oxidação, de estabelecimento e de brotações de gemas axilares de abacaxizeiro cv. Pérola aos 37 dias de cultivo in vitro sob diferentes concentrações de BAP.

\begin{tabular}{cccccc}
\hline \multirow{2}{*}{ Tratamentos } & \multicolumn{2}{c}{ Contaminação } & Oxidação & Estabelecimento & Brotações \\
\cline { 2 - 4 } & Fungo & Bactéria & & & \\
\hline T1 & 0,00 & 6,25 & 18,75 & 75,00 & 37,50 \\
T2 & 0,00 & 6,25 & 0,00 & 93,75 & 75,00 \\
T3 & 0,00 & 6,25 & 0,00 & 93,75 & 75,00 \\
T4 & 0,00 & 6,25 & 0,00 & 93,75 & 68,75 \\
T5 & 0,00 & 6,25 & 0,00 & 93,75 & 87,50 \\
T6 & 0,00 & 0,00 & 0,00 & 93,75 & 81,25 \\
\hline
\end{tabular}

No que diz respeito à morte por oxidação, esta foi observada apenas no tratamento 1, no qual houve uma perda de $18,75 \%$ dos explantes, considerada elevada. As oxidações podem ser oriundas do tratamento de assepsia ou ainda inerentes ao explante. Conforme Moraes et al. (2007), um problema frequente durante o isolamento de explantes é a oxidação de compostos fenólicos, que são liberados pelas células. A oxidação dos polifenóis leva à produção de quinonas, que levam a toxidez e morte das células (OLIVEIRA et al., 2011).

Em relação ao estabelecimento in vitro, todos os tratamentos apresentaram 93,75\% de explantes 
estabelecidos, exceto T1 com 75\% de estabelecimento. Por sua vez, as taxas de brotações foram maiores para os tratamentos contendo maior concentração de BAP, 68,75 a 87,50\% de brotos, enquanto o tratamento controle obteve menos de $40 \%$ de brotações. Dias et al. (2011), ao realizarem estudos com Ananas comosus var. ananassoides verificaram que o tratamento com ausência de reguladores de crescimento apresentou menores médias para o número de brotos. Pesquisas realizadas por Santos (2008) apud Alves et al. (2014) analisando diferentes concentrações de BAP na propagação do abacaxizeiro ornamental inferiu que o meio nutritivo sem o regulador de crescimento foi considerado ineficiente devido à baixa formação de número de brotações por explante. Resultados estes que condizem com os encontrados neste trabalho.

\section{CONCLUSÃO}

A variação da concentração de 6benzilaminopurina (BAP) não influenciou no número de explantes estabelecidos in vitro após 37 dias de cultivo, porém, concentrações entre 0,025 e 0,1 mg L-1 proporcionam um menor tempo de cultivo para o número máximo de explantes estabelecimentos. Na ausência de regulador de crescimento vegetal há baixa taxa de brotações dos explantes.

\section{AGRADECIMENTOS}

Ao Laboratório de Estudo dos Ecossistemas Amazônicos (LEEA) e à Universidade Federal do Oeste do Pará.

\section{REFERÊNCIAS}

ALVES; K. A.; LONDE, L. N.; MELO, E. F.; RODRIGUES, G. B. Multiplicação de abacaxizeiros ornamentais em diferentes concentrações de BAP e períodos de avaliação do desenvolvimento in vitro. Bioscience Journal, Uberlândia, v. 30, p. 188-198, 2014.

AQUIJE, V. M. F. G.; ZORZAL, P. B.; BUSS, D. S.; VENTURA, J. A.; FERNANDES, P. M.; FERNANDES, A. A. Cell wall alterations in the leaves of fusariosis-resistant and susceptible pineapple cultivars. Plant Cell Reports, Heidelberg, v. 29, p. 1109-1117, 2010. 
ARAUJO, R. F.; SIQUEIRA, D. L.; CECON, P. R. Multiplicação in vitro do abacaxizeiro 'Smooth cayenne' utilizando benzilaminopurina (BAP) e ácido naftalenoacético (ANA). Revista Ceres, v. 55, p. 455-460, 2008.

BOTELLA, J. R.; SMITH, M. Genomics of Tropical Crop Plants: Genomics of Pineapple, Crowning The King of Tropical Fruits. Springer, 2008, v. 1, 582 p.

CARVALHO, A. C. P. P. de; PINHEIRO, M. V. M.; DIAS, G. de M. G.; MORAIS, J. P. S. Multiplicação in vitro de abacaxi ornamental por estiolamento e regeneração de brotações. Horticultura Brasileira, v. 27, p.103-108, 2009.

CLEMENT, C. R.; CRISTO-ARAÚJO, M. de; D'EECKENBRUGGE, G. C.; PEREIRA, A. A.; PICANÇO-RODRIGUES, D. Origin and domestication of native Amazonian crops. Diversity, v. 2, p. 72106, 2010.

COELHO, R. I.; CARVALHO, A. J. C.; LOPES, J. C.; TEIXEIRA, S. L.; MARINHO, C. S. Coroa do abacaxi 'Smooth Cayenne' na produção de mudas do tipo rebentão. Ciência e Agrotecnologia, Lavras, MG, v. 31, p. 1867-1871, 2007.

DIAS; M.; PASQUAL, M.; ARAÚJO, A. G.; SANTOS, V. A. dos. Reguladores de crescimento na propagação in vitro de abacaxizeiro ornamental. Revista Brasileira de Ciências Agrárias. v. 6, p. 383-390, 2011.

FRÁGUAS, C. B.; DORNELLES, C. M. V.;
LIMA, G. P. P. In vitro bud induction and multiplication of cV. 'IAC Gomode-mel' pineapple fruit with benzyl amino purine and naphthalene acetic acid. Revista Ciência Rural, v. 39, p. 16821687, 2009.

HOSSAIN, M. D. F.; AKHTAR, S.; ANWAR, M. Nutritional value and Medicinal Benefits of Pineapple. International Journal of Nutrition and Food Sciences, v. 4, p. 84 - 88, 2015.

MENDES, P. dOS S.; ARAÚJO, W.F.; ANTUNES, $F_{\text {; }}$ CHAGAS, E. A.; COUCEIRO, M. A. Cultivo in vitro de plântulas de abacaxizeiro com uso de filtros, ventilação artificial e sacarose. Revista Agro@mbiente On-line, v. 9, p. 202-207, 2015.

MORAES, A. M.; ALMEIDA, F. de A. C.; CAZÉ FIILHO, J. Desinfestação e estabelecimento in vitro de gemas axilares de abacaxizeiro. Tecnologia \& Ciência Agropecuária, v. 1, p. 39-44, 2007.

OLIVEIRA, H. S. de; LEMOS, O. F. de; MIRANDA, V. S.; MOURA, H. C. da P.; CAMPELO, M. F.; SANTOS, L. R. R. dos. Estabelecimento e multiplicação in vitro de brotos no processo de micropropagação de cultivares de bananeira (Musa spp.). Acta Amazônia, v. 41, p. 369-376, 2011.

OLIVEIRA-CAUDURO, Y.; LOPES, V. R.; BONA, C. M. de; ALCANTARA, G. B.; BIASI, L. A. Micropropagação de abacaxizeiro com enraizamento in vitro e ex vitro. Plant Cell Culture \& 
Micropropagation, Lavras, v. 12, p. 5360, 2016.

PASQUAL, M.; SANTOS, F. C.; FIGUEIREDO, M. A. de; JUNQUEIRA, K. P.; REZENDE, J. C.; FERREIRA, E. A. Micropropagação do abacaxizeiro ornamental. Horticultura Brasileira, v. 26, p. 45-49, 2008.

PEREIRA, G. A.; SANTAELLA, M. B.; ALVES, L. M. S. M.; SILVA, E. C. da. Desinfestação in vitro da bananeira 'farta velhaco (sub grupo AAB)' em diferentes concentrações de cloro ativo. Revista Caatinga, Mossoró, v. 28, p. 64-69, 2015.

PICOLOTTO, L.; SCHUCH, M. W.; SOUZA, J. A de; SILVA, L. C.; FERRI, J.; FACHINELLO, J. C. Efeito do hipoclorito de sódio, fotoperíodo e temperatura no estabelecimento in vitro de jabuticabeira. Scientia Agraria, v. 8, p. 19-23, 2007.

SANTOS, M. D. M.; RIBEIRO, D. G.; TORRES, A. C. Brotações adventícias de abacaxizeiro ornamental sob o efeito de benzilaminopurina, ácido naftalenoacético e períodos de subcultivo. Pesquisa Agropecuária Brasileira, v. 43, p. 1115-1120, 2008.

SANTOS, P. C dOs.; FREITAS, S. de J.; FREITAS, M. S. M.; SOUSA, L. B.; CARVALHO, A. J. C. de. Produção de mudas do tipo rebentão, utilizando coroas de três cultivares de abacaxi inoculadas com fungos micorrízicos.

Revista Brasileira de Fruticultura, Jaboticabal - SP, v. 33, p. 954-961, 2011.
SOUZA, F. V. D.; CABRAL, J. R dos S.; SILVA, M. de J.; SANTOS, O. S. N.; FERREIRA, F. R. Evaluation of F1 hybrids between Ananas comosus var. ananassoides and Ananas comosus var. erectifojlius. Acta Horticulturae, v. 822, p. 79-84, 2009. 